\title{
DOES FINANCIAL LITERACY AND FINANCIAL STRESS EFFECT THE FINANCIAL WELLNESS?
}

\author{
Nurazleena Ismail ${ }^{1}$ \\ Faculty of Business and Management, \\ Universiti Teknologi MARA Kelantan, Malaysia \\ (Email: azleena@kelantan.uitm.edu.my) \\ Nur Damia' Amiruddin Zaki ${ }^{2}$ \\ Faculty of Business and Management, \\ Universiti Teknologi MARA Kelantan, Malaysia \\ (Email: myadamia23@gmail.com)
}

Accepted date: $29-04-2018$

Published date: 08-07-2019

To cite this document: Ismail, N., \& Zaki, N. D. A. (2019). Does Financial Literacy and Financial Stress Effect the Financial Wellness? International Journal of Modern Trends in Social Sciences, 2(8), 01-11.

DOI: $10.35631 / \mathrm{IJMTSS} .28001$

\begin{abstract}
Nowadays, people use the financial wellness's as terminology to understand the level of individual's financial condition. Previous researches show that although the persons have a lot of debts, but they feel satisfied with their financial status. Conversely with those who are in good financial wellness with their wealth of life. Additionally, two elements have been discussed in relation to the income earner's financial wellness which are economic well-being and financial well-being. Imbalance of financial wellness among low-medium income earners are due to reducing in employment opportunities, income instability and increase the number of family members. Therefore, the personal financial management is important to ensure good or bad financial wellness among the income earners. In this paper, financial literacy and financial stress are considered to determine the relationship of financial wellness. The result showed that both factors are significant with the strong positive relationship. It is important to describe the ability of income earners manage their money and apply the knowledge to make effective financial decision. Thus, the organization should imply the financial education programs to their employees that can enhance the financial literacy and reduce financial stress. Further research should be explored the other determinant factor such as financial self-efficacy and financial help-seeking behaviour. These factors will improve the low-medium income earners' financial wellness by seeking financial help as well as reducing financial stress.
\end{abstract}

Keywords: Financial Wellness, Financial Literacy, Financial Stress, Income Earners

\section{Introduction}

Recently, the financial program such as motivation and talk have been conducted and designed to improve individual's financial knowledge and outcomes will be measured to look at the 
financial health through the level of financial management either low, medium or high. This is because the financial wellness is important measured using health rather than wealth. According to Delafrooz \& Paim (2011), one of the key components to financial health is a financial wellness. Nowadays, people used the financial wellness's term to understand the level of individual's financial condition. Unfortunately, financial wellness among Malaysians seem to be at lower level cause lack of financial knowledge especially for those who worked in public and private sectors. This situation happened due to different people will define differently about their financial wellness. Some of them feel that they are in good financial wellness even though they have more debt. This is because they feel that their financial in healthy condition. But, some of them feel that they are in a good financial wellness if they are in wealth condition. Thus, the different interpretation of financial wellness leads to the individual's attitude and behaviour in personal financial management (Delafrooz \& Paim, 2011).

In relation to that, there are two elements have been discussed in financial wellness which are economic well-being and financial well-being in differentiating the personal financial management. The changes of financial wellness among the income earners specifically for those who earn low-medium income have been discussed. Delafrooz \& Paim (2011) explored that the changes of financial wellness happened due to decreasing in employment opportunities such as promotion, remuneration, position and self-esteem. In addition, the income instability lead to imbalance of buying power among the households. Furthermore, the increasing number in family members also lead to the changes of financial wellness (Sabitha, 2005). The three situations discussed are evidence from the survey done by Deloitte Millennial Survey (2016) and Paychex (2016). Deloitte Millennial Survey (2016) showed that two-thirds of younger employees plan to leave their current job by 2020, with 25 percent saying they plan to leave in less than a year cause lack of employment opportunities. Paychex survey in 2016 found that approximately 70 percent of employees cited low pay as a reason they have left or would leave a job, and 45 percent said they have or would leave due to a lack of benefits. Most employees are dissatisfied with their pay and benefits because they haven't fully maximized the value of what their company offers. Both surveys will lead to the financial stress among the low-medium income earners. Hence, the aim of this paper is to determine the factors that influence the financial wellness among the low-medium income earners.

Recently, the hottest topic that has really gained in prominence over last year is financial wellness. According to Ward (2017), there has been significant concern and much handwringing about the lack of financial literacy that difficult in fostering the skill. The lack of financial literacy generally puts many families at risk with their decision-making. In Malaysia, the rapid development in modern era give the opportunities in education that created and required people to gain more knowledge especially in daily financial management. This is because with the knowledge in financial, individuals will be more careful and save their money for better situations such as in emergency cases. Unfortunately, previous researches find out that Malaysians have limited knowledge in financial (Lusardi et al, 2010; Chen \& Volpe, 1999; and Henry et al, 2001) because they are not aware about the important of financial literacy. Additionally, American Psychological Association (2014) reports that 64 percent of those surveyed cited money as a significant source of stress and paying for this stress with their health. Financial stress has been attributed to decreased employee productivity, increased absenteeism and increased employer health care costs. Therefore, this paper is aimed to examine the relationship between financial literacy and financial wellness; and the relationship between financial stress and financial wellness. 


\section{Literature Review}

Financial health can be measured by the level of financial wellness of an individual. According to Taft et al, (2013) to know the level of financial health, the individual must know their financial wellness. Nowadays, personal financial planning becomes a genuine issue. This is because the problems in financial not only refer to the poor people, but it refers to the individuals who have income. They are lacking in financial wellness for their daily life cause imbalance of income earn and spending habit. The daily practices of financial wellness may affect the entire decision about money management (Leila \& Fazli, 2015). Moreover, three important components of financial wellness to the income earners are spending, emergencies, and investments. To be financially well, an individual should make a good decision on his/her financial to avoid from spending exceeding income. The planning for emergency fund is a key component of financial wellness. Personal finance experts across the country recommend three to five months of income saved in a separate account for financial emergencies. It is very difficult to be finance well as any unforeseen event without enough emergency savings. In addition, income earners should invest their money either in long-term or short-term investment and diversify their portfolios for value creation. They must ensure the investment decision making will give them good return in future.

Joo \& Grable (2004) initiated a study among the workers with the aim to identify the determinants of financial well-being. It was found that better financial wellness is correlated with reduced absenteeism, better performance appraisal of employees, and minimized loss of working time, meanwhile low level of financial wellness is caused by antecedents for example, financial stress, financial strain $\&$ inadequate financial literacy within employees. Additionally, according to Yin-Fah (2010), financial wellbeing is of the outcome that comes from financial practices that effect the financial wellness among employees. Financial practices refer to the group of people that manage their financial resources to increase their financial success in the retirement planning and financial management growth. Thus, two aspects that related to each of them are financial wellness and employees (Mokhtar et al, 2015). This is because the significant feedback had been received from the observation of employers and financial advisors. Financial wellness will give an affect to both aspects whether directly or indirectly to the employees, groups work and the teams of the company. Initially, the changes of financial wellness level whether high or low among the income earners will affect their job performance.

\section{Financial Literacy}

Financial literacy can be described as the ability to manage money in the world in terms of how people make to earn it and invest to increase the amount of money. According to Ali et al, (2013), it was a component to measure how well the person can use the personal financial information and understand on how to manage the financial. Financial literacy is how people understand about managing money and apply the knowledge to make effective financial decisions. Furthermore, Huston (2010) highlighted a key finding where an individual who had financial literacy may not show the expected behaviour or improve his or her financial wellbeing due to other influences such as cognitive and behaviour. The example of cognitive and behaviour are biased, self-control problems, family, peers, economic and institutional conditions that may affect the financial habits and financial wellness.

Besides, the financial literacy assesses an individual's level of understanding of the basic concepts of finance, and the individual's capability and confidence to manage his or her personal finances (Remund, 2010). The level of understanding in finance will be used to make short-term decisions and appropriate long-term financial planning. It also used in considering 
life events and the ever-changing economic conditions. The other factors that contributed to financial literacy have been found a strong relationship with socio-demographic characteristics and status of family finances (Lusardi, Mitchell \& Curto, 2010). The importance of financial literacy is obvious as it is typically used as an indicator or input to a model that determines the need for financial education and explain variations in behaviour and financial outcomes such as savings, investment and credit behaviour to ensure the good financial wellness.

Therefore, from the arguments of the financial literacy among the individuals that can lead to financial wellness, the hypothesis 1 can be developed as:

H0: There is no significant relationship between financial literacy and financial wellness

H1: There is a significant relationship between financial literacy and financial wellness

\section{Financial Stress}

Financial stress is a condition where individuals facing difficulties in meeting financial obligations as a result shortage in money. A large of amount of debt, medical bills, a job loss or simply being irresponsible with the spending can cause financial stress. According to Wharton (2007) as cited by Lim et al, (2014), he explored that financial stress can lead to decreasing in job performance among employees due to poor financial wellness. Individuals should know how to deal with financial stress by create some strategies that will give benefits to them such as prepare a budget and create emergency fund. Financial stress includes handful aspects of financial prospects such as assets, income, debts and money management. There are several factors have been found to contribute to financial stress such as: 'poor thinking in a financial way and perspective', 'occurrences beyond individual's control', and 'inadequate knowledge and skills' (MacKenzie, Desmond \& Steen, 2013). Poor thinking in financial ways include lack of concern in financial management or want to live exceed own mean and capacity that can influence the financial wellness. Occurrences beyond an individual's controls are for instance, job losses, health or relationship matters like divorce, bearing child rearing cost, unexpected and expected pregnancy, death of spoon feeder and having struggled unstable businesses. The last factor is since some people do not have the sufficient and adequate skills and knowledge about effective financial management.

Furthermore, several researchers defined financial stress as economic stress, hardship, strain and pressure. Financial stress can bring about psychological and physical responses. For examples where one's health has been affected by financial stress are having drinking problems, physical impairments, depression and deteriorating psychological well-being (Kim \& Garman, 2003). A few factors which used as financial stress measures are as such: insufficient income allocated for repairs of household equipment or personal vehicles, borrow money to buy necessities goods, improper planning of budget allocated for prioritized requirements, sickness, and poor skills and abilities needed for certain jobs that possess transferability, insurance, promotions and fringe benefits.

Due to the several arguments of financial stress towards the financial wellness, the hypothesis 2 is developed as:

H0: There is no significant relationship between financial stress and financial wellness

$\mathrm{H} 2$ : There is a significant relationship between financial stress and financial wellness

\section{Theoretical Framework}

The Figure 1 shows the theoretical framework of two variables that involved in this research. There are consists of independent variables which are financial literacy (Henry et al, 2001; 
Delafrooz; 2011, Murphy, 2005; Lusardi et al, 2010; Chen \& Volpe, 1999;) and financial stress (Delafrooz; 2011, Leila \& Fazli; 2015). Meanwhile, the dependent variable is financial wellness among employees in government sector.

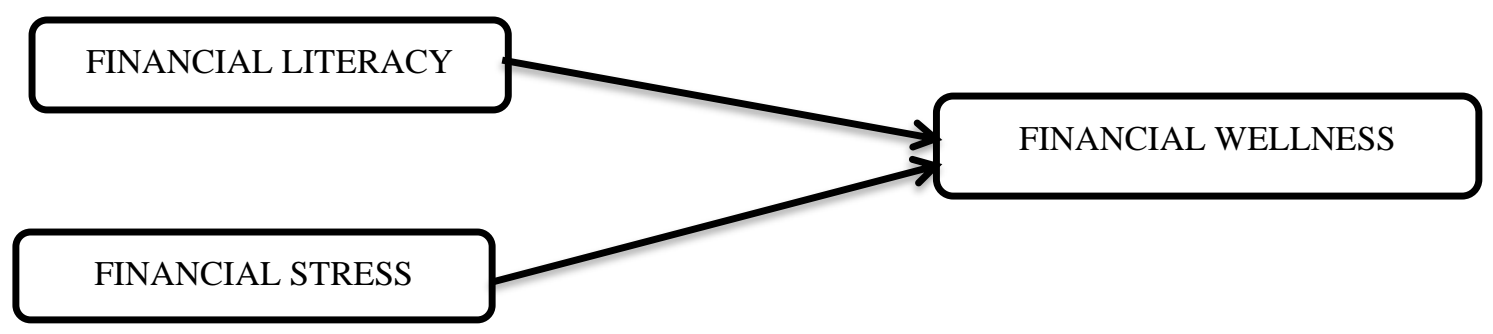

Figure 1: Theoretical Framework

\section{Methodology}

This quantitative study was conducted to examine and explain the characteristics of all variables identified. Data was collected using the individual as a unit of analysis. The questionnaire is self-administered and constructed in dual-language which is English and Malay that consisted of four sections. Section A consists of demographic profile and section B, C and D consist of five-point likert scale of six questions related to financial wellness, financial literacy and financial stress respectively. The respondents should response from point $1=$ strongly disagree to $5=$ strongly agree. The population of this study consisted of low-medium income earners among supporting staff in Universiti Malaysia Kelantan (UMK). Selected respondents were served in finance department, human resource department, academic affair department and library department. To determine the sample size, the researcher used the table by Sekaran and Bougie (2014) to decide 140 sample size to represent the entire population of UMK. The probability sampling is used in this study. The researcher used stratified random sampling technique to split the respondents into mutually exclusive groups. The registrar office provides the list names and positions of the employees in each of the selected departments. Finally, based on the positions of the employees, the questionnaires are self-distributed to 50 employees from Finance Department, 30 employees from Human Resources Department, 30 employees from Academic Affair Department and 30 employees from Library Department. The data are gathered from the feedback of the distributed questionnaires and analysed using Statistical Package for the Social Science (SPSS) 20.0. There are three hypotheses are developed in this study in order to ensure the objectives of the study are achieved.

\section{Findings}

Out of the 140 respondents who were selected for this study, a total of 103 questionnaires were returned the questionnaires which is $73.6 \%$ are responded. In Section A of the questionnaire, information was obtained on 7 demographic characteristics and basic information related to respondent which are gender, age, marital status, race, academic qualification, monthly income and working experience. Table 1 summarizes the demographic characteristics of respondents.

Table 1: Respondents' Demographic Characteristic

\begin{tabular}{|l|l|l|}
\hline Description & Frequency & Percentage \\
\hline $\begin{array}{l}\text { Gender: } \\
\text { Male }\end{array}$ & 49 & 47.6 \\
\hline
\end{tabular}




\begin{tabular}{|l|l|l|}
\hline Female & 54 & 52.4 \\
\hline Age: & & \\
18-25 years & 21 & 20.4 \\
26-35 years & 48 & 46.6 \\
36-45 years & 21 & 20.4 \\
46-55 years & 13 & 12.6 \\
\hline Marital Status: & & \\
Single & 38 & 36.9 \\
Married & 62 & 60.2 \\
Others & 2 & 1.9 \\
\hline Race: & 103 & \\
Malay & 0 & 100 \\
Chinese & 0 & 0 \\
Indian & 0 & 0 \\
Others & 11 & 0 \\
\hline Academic qualification: & & \\
SPM & 20 & 10.7 \\
Diploma & 63 & 19.4 \\
Bachelor & 9 & 61.2 \\
Masters & & 8.7 \\
\hline Monthly income: & \\
RM 1,000 - RM 2,000 & 31 & 30.1 \\
RM 2,001 - RM 3,000 & 43 & 41.7 \\
RM 3,001 - RM 4,000 & 15 & 14.6 \\
RM 4,001 - RM 5,000 & 14 & 13.6 \\
\hline Working experience: & & \\
Less than one year & 25 & 24.3 \\
2-5 years & 59 & 57.3 \\
6-10 years & 18 & 17.4 \\
More than 10 years & 1 & 1.0 \\
\hline
\end{tabular}

From the table 1, it shows that most respondents are female with $52.4 \%$. The respondents are at the age ranging from 26 to 35 years old. Most of the respondents are married and all respondents are Malay. They are mostly having a bachelor's degree. About $41.7 \%$ of the respondents earn monthly income between RM 2001 to RM 3,000. The respondents are mostly having 2 to 5 years working experience.

The reliability test is used to examine the consistency of factors identified among the items in five-point likert scale questionnaires. From the analysis, all the items for each variable are reliable and acceptable with the Cronbach's alpha value of 0.803, 0.928 and 0.962 for financial wellness, financial literacy and financial stress respectively. It means that all the questions can be trusted to determine the finding of the research.

The descriptive statistics is utilized to translate mean of the outcome that highlighted for question that utilized interval estimation. The mean value is divided into three level which are high $(3.50-5.00)$, medium $(3.49-2.50)$ and low $(2.49-1.00)$. Therefore, table 2 reveals the mean value for each items of financial wellness that the highest mean value of 4.1942 is refer to most of the respondents are concern with their financial performance. But, it followed with the mean value of 3.5728 is refer to most of the respondents are less properly plan their 
spending. It is because their income finished before they are receiving the next income among low-medium income earners. But, the respondents still have an emergency fund with the mean value of 3.5243. The low mean value of 3.3592 is represents to the respondents are occasionally facing the problems to pay utility bills and insurance premium. It can say that the level of financial wellness of respondents are medium when they confident on controlling their personal financial and their financial management in a good condition.

Table 2: Descriptive Statistic for Financial Wellness

\begin{tabular}{|l|c|}
\hline \multicolumn{1}{|c|}{ Questions } & Mean \\
\hline $\begin{array}{l}\text { I am always finishing my earnings } \\
\text { before receiving new income. } \\
\text { I am often facing problems with } \\
\text { bills such as telephone, credit } \\
\text { cards, insurance payments and etc. }\end{array}$ & 3.5728 \\
$\begin{array}{l}\text { I am confident that I can control } \\
\text { my personal financial. }\end{array}$ & 3.4757 \\
$\begin{array}{l}\text { I know that my financial } \\
\text { management is in a good } \\
\text { condition. }\end{array}$ & 3.4951 \\
$\begin{array}{l}\text { I am feasible to have an emergency } \\
\text { earning at least RM1000 if needed. }\end{array}$ & 3.5243 \\
$\begin{array}{l}\text { I am concern with my overall } \\
\text { financial performance. }\end{array}$ & 4.1942 \\
\hline
\end{tabular}

For the financial literacy, table 3 signifies all questions have the highest mean value. It means that all respondents have financial literacy where they are concerned on saving and investment. Nevertheless, most of the respondents will take a loan for their investment and they are spending more on buying necessities goods than saving their income. 
Table 3: Descriptive Statistic for Financial Literacy

\begin{tabular}{|c|c|}
\hline Questions & Mean \\
\hline $\begin{array}{l}\text { I tend to spend more than saving } \\
\text { in buying necessities goods. }\end{array}$ & 4.1650 \\
\hline $\begin{array}{l}\text { I believe that buying insurance } \\
\text { is the best form of investment. }\end{array}$ & 4.1262 \\
\hline $\begin{array}{l}\text { I think that a family should have } \\
\text { an emergency saving at least } 3 \\
\text { months of the family income. }\end{array}$ & 4.1359 \\
\hline $\begin{array}{l}\text { I think that saving account is } \\
\text { better than fixed deposit } \\
\text { account. }\end{array}$ & 4.1068 \\
\hline $\begin{array}{l}\text { I know that the savings is } \\
\text { doubled its value after } 10 \text { years. }\end{array}$ & 4.1068 \\
\hline I can take loan for investment. & 4.2621 \\
\hline
\end{tabular}

Referring to table 4, most of low-medium income earners have high financial stress. They are suffered on thinking about the bill payments, medical expenses and accrual payment. Worrying on high medical expenses will lead them restless and less peace of mind. They are also unable to support themselves in eating better foods and suffering depression due to their financial situation in every month.

Table 4: Descriptive Statistic for Financial Stress

\begin{tabular}{|l|c|}
\hline \multicolumn{1}{|c|}{ Questions } & Mean \\
\hline $\begin{array}{l}\text { Delay in payment always makes } \\
\text { me worry. }\end{array}$ & 4.1068 \\
$\begin{array}{l}\text { I cannot sleep because of } \\
\text { worrying over bill payments. } \\
\text { I am not able to support myself } \\
\text { financially in eating a better food. }\end{array}$ & 4.2816 \\
$\begin{array}{l}\text { I am suffering depression } \\
\text { because of my financial situation } \\
\text { for every month. } \\
\text { I worry over the medical cost. } \\
\text { The current financial conditions } \\
\text { make me more restless and not in } \\
\text { mood. }\end{array}$ & 4.0097 \\
\hline
\end{tabular}


Furthermore, to in line with the objective of the study, the Pearson correlation is used to find correlation between variables and the value is between 0.00 which is no correlation and 1.0 for perfect correlation.

Table 5 shows the correlation for all variables in the study. The hypothesis statement 1 for first variable is financial literacy (independent variable) is $\mathrm{H} 0: \beta \mathrm{X}_{1}=0$ and $\mathrm{H} 1: \beta \mathrm{X}_{1} \neq 0$. The decision is $\mathrm{P}$-value $=0.000<0.05$, so reject $\mathrm{H} 0$ because there is a significant relationship between financial literacy and financial wellness among government employees. Pearson's correlation for this analysis shows that there is very strong correlation and positive relationship which is 0.872 . The hypothesis statement 2 for second variable is financial stress (independent variable) is $\mathrm{H} 0: \beta \mathrm{X}_{2}=0$ and $\mathrm{H} 2: \beta \mathrm{X}_{2} \neq 0$. The decision is $\mathrm{P}$-value $=0.000<0.05$ so reject $\mathrm{H} 0$ because there is a significant relationship between financial stress and financial wellness among government employees. Pearson's correlation for this analysis shows that there is very strong correlation and positive relationship which is 0.852 .

Table 5: Correlation for All Variables

\begin{tabular}{|c|c|c|c|c|}
\hline & & WELLNESS & LITERACY & STRESS \\
\hline \multirow[t]{3}{*}{$\begin{array}{l}\text { WELLNES } \\
\text { S }\end{array}$} & $\begin{array}{l}\text { Pearson } \\
\text { Correlation }\end{array}$ & 1 & $.872^{* *}$ & \\
\hline & Sig. (2-tailed) & & .000 & .000 \\
\hline & $\mathrm{N}$ & 103 & 103 & 103 \\
\hline \multirow[t]{3}{*}{ LITERACY } & $\begin{array}{l}\text { Pearson } \\
\text { Correlation }\end{array}$ & $.872^{* *}$ & 1 & $.916^{* * *}$ \\
\hline & Sig. (2-tailed) & .000 & & .000 \\
\hline & $\mathrm{N}$ & 103 & 103 & 103 \\
\hline \multirow[t]{3}{*}{ STRESS } & $\begin{array}{l}\text { Pearson } \\
\text { Correlation }\end{array}$ & $.852^{* *}$ & $.916^{* *}$ & 1 \\
\hline & Sig. (2-tailed) & .000 & .000 & \\
\hline & $\mathrm{N}$ & 103 & 103 & 103 \\
\hline
\end{tabular}

\section{Discussion}

An immediate and beneficial outcome on monetary health may occur when the individual has knowledge in finance (Sabri and Falahati, 2013). As supported by Azwadi et al. (2013) explained that people with high money related proficiency tend to arrange well in their spending and funds. Overall results represent that the respondents who are low-medium income earners have medium level of financial wellness even they have good financial literacy. It is because most of them facing with the high financial stress. It means that good financial literacy will not secure of better way in financial management due to lack of practising precise financial way from what knowledge that they have. Most of the respondents also live exceeding own mean and capacity due to low salaries received. This may occur due to depression and deteriorating psychological well-being (Kim \& Garman, 2003). Other than that, low-medium income earners facing financial stress due to insufficient income allocated for repairs of household equipment or personal vehicles, borrow money to buy necessities goods and improper planning of budget 
allocated for prioritized requirements. From that reason, the result shows that there is a significant relationship between financial stress and financial wellness. Therefore, the company or organisation essentially to invest and do benefit-plan in high-quality financial wellness program in a workplace to increase employees' financial knowledge and monetary health. Hewitt (2015) found that $76 \%$ of employers plan to expand their focus on the financial wellbeing of their employees in 2014 and beyond. It happens because, employers have the awareness about the financial management and the important of financial wellness towards the future of their employees.

\section{Conclusion}

As a conclusion, financial wellness become one of the hottest and most discussed topics among the community related to financial management. Most of the organisations need to provide training in financial wellness due to the results showed that the employees are facing with the financial stress even they have knowledge in financial. Therefore, it will lead to the low performance in workplace. Additionally, the employees' financial wellness is important measured using health rather than wealth. This is because most of the employees are unhealthy due to suffer on financial depression. The understanding of the financial management is important to avoid the financial depression. The employee also needs to understand the concept of financial wellness because it will consider they are being financially well. For future research, the researcher should consider financial self-efficacy and financial help-seeking behaviour to determinant the financial wellness. These factors will improve the low-medium income earners' financial wellness by seeking financial help as well as reducing financial stress.

\section{References}

Ali, A., Rahman, M. S. A., \& Bakar, A. (2013). Financial Literacy and Satisfaction in Malaysia: A Pilot Study. International Journal of Trade, Economics and Finance, 4(5), 319-324.

American Psychological Association. (2015). "Stress in America: Paying With Our Health". Press Release. Feb. 4, 2015. https://www.apa.org/news/press/releases/ stress/2014/stress-report.pdf.

Consumer Financial Protection Bureau. (2015). Financial well-being: The goal of financial education

Delafrooz, N., \& Paim, L. H. (2013). Role of financial stress on relationship between financial problem and financial wellness among Malaysia workers. African Journal of Business Management. 7(20), 1966-1972.

Deloitte. (2016). "The Deloitte Millennial Survey 2016: Millennials Have One Foot Out the Door”.https://www2.deloitte.com/global/en/pages/about-deloitte/articles/gx millennials-one-foot-out-the-door.html.

Falahati, L., \& Sabri, M. F. (2015). An exploratory study of personal financial wellbeing determinants: Examining the moderating effect of gender. Asian Social Science, 11(4), 33-42.

Garman, E.T., Kim, J., Kratzer, C. Y., Brunson, B. H., \& Joo, S. (1999). Workplace Financial Education Improves Personal Financial Wellness.

Hewitt, A. (2015). Aon Hewitt Survey Shows Employers are Offering More Tools and Resources to Improve Financial Outcomes for Workers. http://ir.aon.com/aboutaon/investor-relations/investor-news/news-release-details/2015/Aon-Hewitt-SurveyShows-Employers-are-Offering-More-Tools-and-Resources-to-Improve-FinancialOutcomes-for-Workers/default.aspx

Huston SJ (2010). Measuring financial literacy. Journal of Consumer Affairs 44 (2), 296 - 316. 
Joo, S., \& Garman, E. T. (1998). The potential effects of workplace financial education based on the relationship between personal financial wellness and worker job productivity. Personal Finances and Worker Productivity, 2(1), 163-74

Joo, S., \& Grable, J. E. (2004). An exploratory framework of the determinants of financial satisfaction. Journal of Family and Economic Issues, 25(1), 25-50.

Kim, J., \& Garman, E. T. (2003). Financial stress and absenteeism: An empirically derived research model. Financial Counseling and Planning, 14(1), 1-13.

Lim, H., Heckman, S. J., Letkiewicz, J. C., \& Montalto, C. P. (2014). Financial Stress, SelfEfficacy, and Financial Help-Seeking Behavior of College Students. Journal of Financial Counseling and Planning, 25(2), 148-160.

Lusardi A, Mitchell OS, Curto V. (2010). Financial Literacy among the young: evidence and implications for consumer policy. Journal of Consumer Affairs 44 (2), 358 - 380

MacKenzie, D., Desmond, K., \& Steen, A. (2013). Household organisational management expenses advice program evaluation report, Commonwealth Department of Families, Housing, Community Services and Indigenous Affairs. Commonwealth of Australia, Canberra.

Mohamad Fazli Sabri. \& Leila Falahati. (2015). Predictors of financial well-being among Malaysian employees: Examining the mediate effect of financial stress. Journal of Emerging Economies and Islamic Research, 1(3).

Paychex. (2016). "Employee Retention: What Makes Employees Stay or Leave”. Human Resources Survey. Aug. 19, 2016. https://www.paychex.com/articles/human resources/employee-retention-what-makes-employees-stay-leave.

Remund DL. (2010). Financial literacy explicated: The case for clearer definition in an increasingly complex economy. Journal of Consumer Affairs 44 (2), 276 - 295.

Sabitha Marican. (2005). Kaedah Penyelidikan Sains Sosial. Petaling Jaya, Selangor: Prentice Hall.

Sabri, M. F., \& Zakaria, N. F. (2015). The Influence of Financial Literacy, Money Attitude , Financial Strain and Financial Capability on Young Employees ' Financial, Social Sciences \& Humanities 23(4), 827-848.

Sekaran, U., \& Bougie, R. (2014). Research Methods for Business: A skill-building approach. Chichester, West Sussex: Wiley.

Ward, G. (2017). Calculating ROI: Measuring the Benefits of Workplace Financial Wellness. Pension Section, 24. 